\title{
Bazı Penisilinlerin Farmasötik Dozaj Formlarından Voltametrik Tayinleri
}

\author{
Sabriye Perçin Özkorucuklu ${ }^{1 *}$, Mehmet Sarı ${ }^{2}$ Gizem Yıldırım Baştemur ${ }^{3}$ \\ ${ }^{1}$ İstanbul Üniversitesi, Fen Fakültesi, Moleküler Biyoloji ve Genetik Bölümü, 34134, İstanbul, Türkiye (ORCID: 0000-0001-9778-2034) \\ ${ }^{2}$ Süleyman Demirel Üniversitesi, Fen Edebiyat Fakültesi, Kimya Bölümü, 32260, Isparta, Türkiye (ORCID: 0000-0001-9963-270X) \\ ${ }^{3}$ İstanbul Üniversitesi, Fen Bilimleri Enstitüsü, Moleküler Biyoloji ve Genetik Program1, 34134, İstanbul, Türkiye (ORCID: 0000-0002-4634-4525)
}

(İlk Geliş Tarihi 22 Kasım 2019 ve Kabul Tarihi 19 Aralık 2019)

(DOI: $10.31590 /$ ejosat.649740)

\begin{abstract}
ATIF/REFERENCE: Özkorucuklu, S. P., Sarı, M. \& Baştemur, G. Y. (2019). Bazı Penisilinlerin Farmasötik Dozaj Formlarından Voltametrik Tayinleri. Avrupa Bilim ve Teknoloji Dergisi, (17), 989-994.

\section{$\ddot{O} \mathbf{z}$}

Diferansiyel puls voltametrisi ile ilaç analizleri ilaç endüstrisinde, klinik analizlerde ve biyosensör tasarımında kullanımı giderek artan oldukça yararlı bir tekniktir. Bu teknik diğer analitik yöntemlere alternatif ve tamamlayıcıdır. Basit, hızlı, duyarlı ve seçici olması, uzun ve zaman alıcı ayırma basamaklarına ihtiyaç duymaması gibi nedenlerden dolayı da diğer analitik tekniklerden ayrılmaktadır. Bu çalışmada antibiyotik tedavisinde kullanılan ampisilin ve penisilin $\mathrm{V}$ bileşiklerinin kalem ucu grafit elektrot yüzeyindeki elektrokimyasal davranışları diferansiyel puls voltametri yöntemiyle incelenmiştir. Bileşiklerin elektrokimyasal davranışları üzerine destek elektrolit ve $\mathrm{pH}$ 'nın etkileri belirlenmiştir. Ampisilin ve penisilin $\mathrm{V}$ için kalibrasyon grafikleri sırasıyla $2,0.10^{-5}-2,0.10^{-4} \mathrm{M}$ ve $5,0.10^{-4}-1,0.10^{-2} \mathrm{M}$ derişim aralı̆̆ında lineerdir ve dedeksiyon limitleri (LOD) 4,05.10 $10^{-7}$ ve $3,07.10^{-5} \mathrm{M}$ olarak bulunmuştur. Geliştirilen yöntem ilaç etken maddelerin farmasötik dozaj formlarından miktar tayinlerine uygulanmış ve yöntemin geri kazanım değerlerinin \% 100'e yakın olduğu belirlenmiştir.
\end{abstract}

Anahtar Kelimeler: Ampisilin, Penisilin V, İlaç analizi, Kalem ucu grafit elektrot, Diferansiyel puls voltametri.

\section{Voltammetric Determinations of Some Penicillins in Pharmaceutical Dosage Forms}

\begin{abstract}
Drug analysis by differential pulse voltammetry is quite a useful technique which is increasingly used in pharmaceutical industry, clinical analysis and design of biosensor. It is an alternative or complimentary to other analytical methods. This technique is also separated from other analytical techniques due to it's simple, rapid, sensitive, selective and without the need for long and timeconsuming separation steps. In this study, electrochemical behaviors of ampicillin and penicillin V used in treatment of antibiotic were investigated on pencil graphite electrode by differential pulse voltammetry method. Effects on electrochemical behavior of supporting electrolyte and $\mathrm{pH}$ were determined. The calibration graphs were linear in the ranges of $2.0 .10^{-5}-2.0 .10^{-4} \mathrm{M}$ ve $5.0 .10^{-4}-1.0 .10^{-2} \mathrm{M}$ and detection limits (LOD) were found as $4.05 .10^{-7}$ ve $3.07 .10^{-5} \mathrm{M}$, for ampicillin and penicillin V, respectively. The developed method was applied to the quantification of pharmaceutical active compounds from pharmaceutical dosage forms and recovery values of the method were determined which is quite close to $100 \%$.
\end{abstract}

Keywords: Ampicillin, Penicillin V, Drug analysis, Pencil graphite electrode, Differential pulse voltammetry.

\footnotetext{
* Sorumlu Yazar: İstanbul Üniversitesi, Fen Fakültesi, Moleküler Biyoloji ve Genetik Bölümü, 34134, İstanbul, Türkiye, ORCID: 0000-0001-97782034, sabriyeo@istanbul.edu.tr
} 


\section{Giriş}

Antibiyotikler, tüm tıp tarihinde mucize ilaçlar olarak kabul edilebilecek nadir ilaçların başında gelmektedirler. Bu özellikleri nedeni ile antibiyotikler, tüm dünyada en yaygın kullanılan ilaçların arasında yer almaktadır [Akalın,1994]. Antibiyotikler, bakteri veya mantarlar tarafından sentezlenen, diğer mikroorganizmaların gelişimini engelleyen ve sonuçta onların ölümüne yol açan maddelerdir. Bugüne kadar yüzlerce antibiyotik tanımlanmış olup bunların önemli bir bölümü geliştirilerek enfeksiyon hastalıklarının tedavisinde kullanılmaktadır [Yanmaz, 2010]. Beta-laktam ( $\beta$-laktam) antibiyotikler, gerek hastane içinde gerekse hastane dışında en sık kullanılan antibiyotik türevlerinin başında gelmektedir [Gökahmetoğlu, 1997]. $\beta$-laktam grubu antibiyotiklerden en çok bilinen grup olan penisilinler, bakteri ve mantar enfeksiyonlarını önlemek için veterinerlik ve tıbbi ilaç uygulamalarında yaygın olarak kullanılmaktadırlar [Svorc vd., 2012a].

Ampisilin yarı sentetik bir penisilindir (Şekil 1). Ampisilin, penisilin notatum ve penisilin chrysogenum'un çeşitli suşları kullanılarak biyosentetik süreç ile hazırlanan benzilpenisilin veya penislin G'den üretilmektedir. Ampisilin doğada asidiktir ve bakteriyel hücre duvarının protein sentezinin inhibesinde rol oynar [Khan vd., 2015]. Penisilin V ve onun potasyum tuzu, küçük spektrumlu $\beta$-laktam antibiyotikler grubuna aittir (Şekil 1). Penisilin V, hücre duvarı mukopeptidinin biyosentez inhibisyonu boyunca rol oynar [Medvedovici vd., 2002].

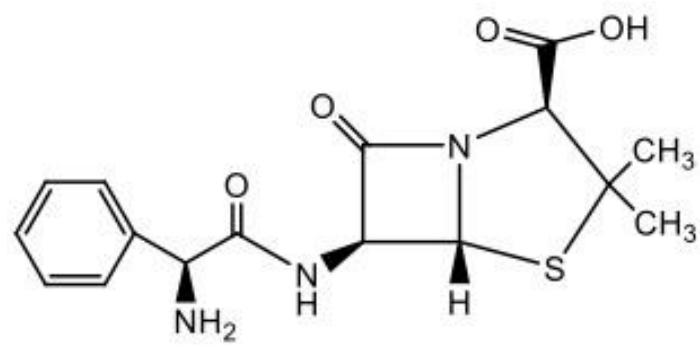

Ampisilin<smiles>CC1(C)S[C@@H]2[C@H](NC(=O)COc3ccccc3)C(=O)N2[C@H]1C(=O)O</smiles>

Penisilin V

Şekil 1. Çalışılan bileşiklerin kimyasal yapıları

İlaç analizlerinde kromatografik ve spektrometrik yöntemlere alternatif yöntem olarak nitelendirilen modern voltametri, bu yöntemlerle yarışmalı olmaktan çok onları tamamlayıcı niteliktedir. Pek çok ilaç etken maddesi ve vücutta bulunan fizyolojik aktif maddeler voltametrik ve polarografik yöntemlere cevap vermektedir. Bu yöntemlerin eczacılık alanında ve klinik çalışmalarda yaygın olarak kullanılmasının nedeni düşük derişimlerde farmasötik analizlerin yapılabilmesi, numunelerin kolayca ve çok kısa bir sürede hazırlanabilmesi, analiz süresinin kısa olması, ortamda bulunan katkı maddelerinin veya safsızlıkların analiz sonucunu etkilememesidir. Tablet, kapsül, süspansiyon, şurup vb. ilaç formülasyonlarının çözünmeyen kısımlarının veya katkı maddelerinin elektroaktiviteleri bulunmadığı için herhangi bir ayırma işlemine gerek olmadan analizleri yapılabilmektedir [Altınöz Erdoğan, 2011; Perçin Özkorucuklu vd., 2008; Özcan vd., 2008; Gürler vd., 2008]. Voltametrik yöntemler arasında diferansiyel puls voltametrisi günümüzde ilaç endüstrisi, klinik analizleri, çevre analizleri ve biyosensör tasarımları da dâhil olmak üzere pek çok alanda kullanılmaktadır [Lima vd., 2014; Aydogdu vd., 2014; Das vd., 2014].

$\mathrm{Bu}$ çalışmada, penisilin grubu bileşiklerinden ampisilin ve penisilin V'nin elektrokimyasal davranışları, kalem grafit elektrot yüzeyinde diferansiyel puls voltametri (DPV) yöntemiyle incelenmiştir. Farklı tampon ve pH değerlerinde elde edilen sonuçlar değerlendirilerek her bir bileşik için optimum koşullar belirlenmiştir. Bu etken maddelerin farmasötik örneklerdeki tayinleri belirlenen optimum koşullarda gerçekleştirilmiştir.

\section{Materyal ve Metot}

Deneylerde kullanılan tüm kimyasal maddeler analitik veya HPLC saflıktadırlar. Deneylerin tamamında direnci $18 \mathrm{M} \Omega \mathrm{cm}$ olan deiyonize su kullanılmıştır. Elektrokimyasal ölçümler GPES 4.9 yazılım programlı, Autolab Potansiyostat/ Galvanostat PGSTAT-302N cihazı kullanılarak üç elektrot sistemli elektrokimyasal hücrede gerçekleştirilmiştir. Karşıt elektrot olarak platin tel, referans elektrot olarak sulu $\mathrm{Ag} / \mathrm{AgCl}$ ve çalışma elektrodu olarak da karbon bazlı kurşun kalem ucu (0,7 mm çaplı, 2B) kullanılmıştır. Tampon çözeltilerin pH ölçümleri Mettler Toledo S220 Seven Compact pH/iyon metre ve Mettler Toledo InLab $416 \mathrm{Ag} / \mathrm{AgCl}$ kombine elektrot kullanılarak yapılmıştır. Çözeltilerin hazırlanmasında ve elektrotların temizlenmesinde ultrasonik banyo (Elmasonic S15) kullanılmıştır. 


\subsection{Kullanılan Çözeltiler}

Penisilin grubu bileşiklerin pik gerilimleri ve akımları üzerine $\mathrm{pH}$ 'nın etkisi, $0,2 \mathrm{M}$ asetat (pH 3,5;4;4,5;5;5,5;6), 0,2 M fosfat $(\mathrm{pH} 2 ; 3 ; 4 ; 5 ; 6 ; 7 ; 8)$ ve geniş pH aralığında çalışma imkânı sağlayan $0,04 \mathrm{M}$ britton-robinson tampon $(\mathrm{pH} 3 ; 4 ; 5 ; 6 ; 7 ; 8 ; 9 ; 10 ; 11)$ çözeltilerinde incelenmiştir. Ampisilin ve penisilin V'nin $0,1 \mathrm{M}$ stok çözeltileri olarak hazırlanmış ve $+4{ }^{\circ} \mathrm{C}$ 'de saklanmıştır. Ampisilin tayini için Ampisina (Mustafa Nevzat) isimli ilaç örneğinden 4 tablet alınıp tartıldıktan sonra havanda ezilerek toz haline getirilmiş ve manyetik karıştırıcıda pH'sı 5,0 olan 0,2 M asetat tamponunda çözülerek hacim $20 \mathrm{~mL}$ 'ye tamamlanmıştır. Daha sonra süzülerek süzüntü $+4{ }^{\circ} \mathrm{C}$ 'da saklanmıştır. Hazırlanan ampisilin çözeltisinin derişimi yaklaşık $20 \mathrm{mM}$ 'dır. Penisilin V'nin tayininde kullanılan PENOS 1000 (Sandoz) ilaç örneğinden 4 tablet alınmış, havanda ezilerek toz haline getirilmiş ve pH'sı 6,0 olan Britton-Robinson tamponunda çözülerek hacmi $25 \mathrm{~mL}$ 'ye tamamlanmıştır. Bu çözelti süzülerek $+4{ }^{\circ} \mathrm{C}$ 'de saklanmıştır. Penisilin V'nin çözeltisinin derişimi yaklaşık olarak $25 \mathrm{mM}$ 'dır.

\subsection{Penisilinlerin Elektrokimyasal Davranışları Üzerine pH Etkisinin İncelenmesi}

Çalışılan penisilin grubu antibiyotiklerin elektrokimyasal davranışları, farklı pH değerlerinde hazırlanan asetat, fosfat ve brittonrobinson tampon çözeltilerinde kalem ucu grafit elektrot kullanılarak diferansiyel puls voltametrisi (DPV) yöntemi ile belirlenmiştir. Penisilin çözeltileri ilave edilmeden önce kalem ucu grafit elektrodu ile tüm tampon çözeltilerinde diferansiyel puls voltamogramları 5'er kez alınarak boş çözelti davranışları belirlenmiş ve sonrasında çalışılan tampon ortamlarında hazırlanan ampisilin ve penisilin $\mathrm{V}$ stok çözeltilerinden elektrokimyasal hücreye eklenerek DP voltamogramları kaydedilmiştir. Voltamogramlar karşılaştırılarak bileşiklere ait pikler belirlenmiştir. Tüm diferansiyel puls ölçümleri $0,0 \mathrm{~V}$ ile $+2,0 \mathrm{~V}$ gerilim aralığında 5'er kez alınmış ve elde edilen voltamogramlardan ortalama pik akımları ve gerilimleri belirlenmiştir. Bileşiklere ait pik akım ve gerilimlerinin Britton-Robinson, asetat ve fosfat tamponlarındaki değişimleri incelenmiştir.

\subsection{Farmasötik Numunelerde Ampisilin ve Penisilin V'nin Elektrokimyasal Tayini}

Ampisilin ve penisilin V'nin elektrokimyasal davranışlarının incelenmesi sonucunda bileşiklere ait yükseltgenme pik akımlarının maksimum olduğu çözeltiler belirlenmiştir. Bu çözeltide kalem ucu grafit elektrodu kullanılarak ampisilin için 0,02-0,20 mM, penisilin V için 0,5-10 mM derişim aralığında DPV yöntemi ile ölçülen yükseltgenme pik akımları grafiğge geçirilerek kalibrasyon grafikleri elde edilmiştir. Daha sonra kalibrasyon doğrusu aralığında bulunan derişimlerde seyreltilmiş ilaç örnekleri, tampon çözelti içerisine ilave edilmiş ve farmasötik numunedeki ampisilin ve penisilin V, kalem ucu grafit elektrot kullanılarak DPV yöntemi ile tayin edilmiştir.

\section{Araştırma Sonuçları ve Tartışma}

Kalem ucu grafit elektrot ile çalışılan tampon çözelti içerisine çalışılan bileşiğin ilave edilmeden önce (a) ve ilave edildikten sonra (b) alınan diferansiyel puls voltamogramları karşılaştırılarak bileşiklerin yükseltgenme gerilimi belirlenmiştir. Ampisilin için yükseltgenme gerilimi yaklaşık $+0,90 \mathrm{~V}$ (Şekil 2a), penisilin V için yaklaşık $+1,70 \mathrm{~V}$ (Şekil 2b) olarak bulunmuştur.

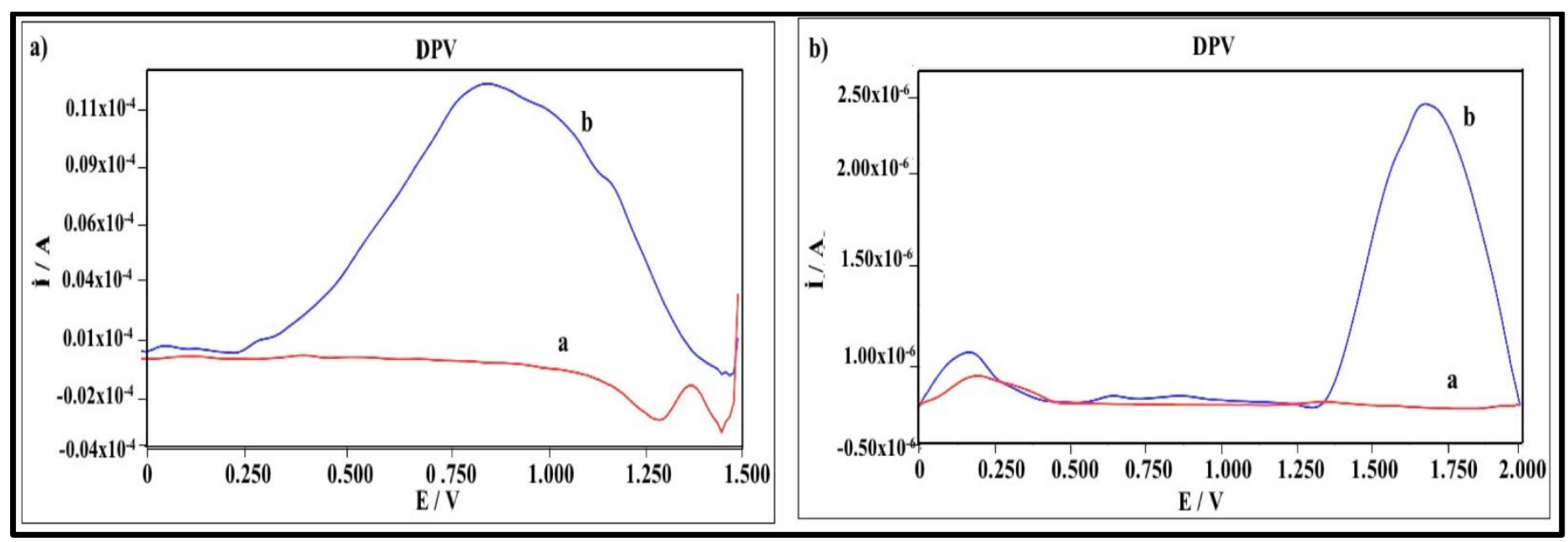

Şekil 2. a) Ampisilin bulunmayan ve 0,2 mM ampisilin içeren b) Penisilin V bulunmayan ve 5,0 mM penisilin V içeren çözeltide alınan DP voltamogramlarının karşılaştırılması

Bileşiklerin elektrokimyasal davranışı üzerine pH'nın etkisi farklı pH aralıklarında hazırlanan asetat, fosfat ve britton-robinson tampon çözeltilerinde incelenmiştir. En yüksek akım değeri ampisilin için pH 5,0 asetat tamponunda (Şekil 3a), penisilin V için pH 8,0 Britton-Robinson tampon çözeltisinde (Şekil 3b) elde edilmiştir. 

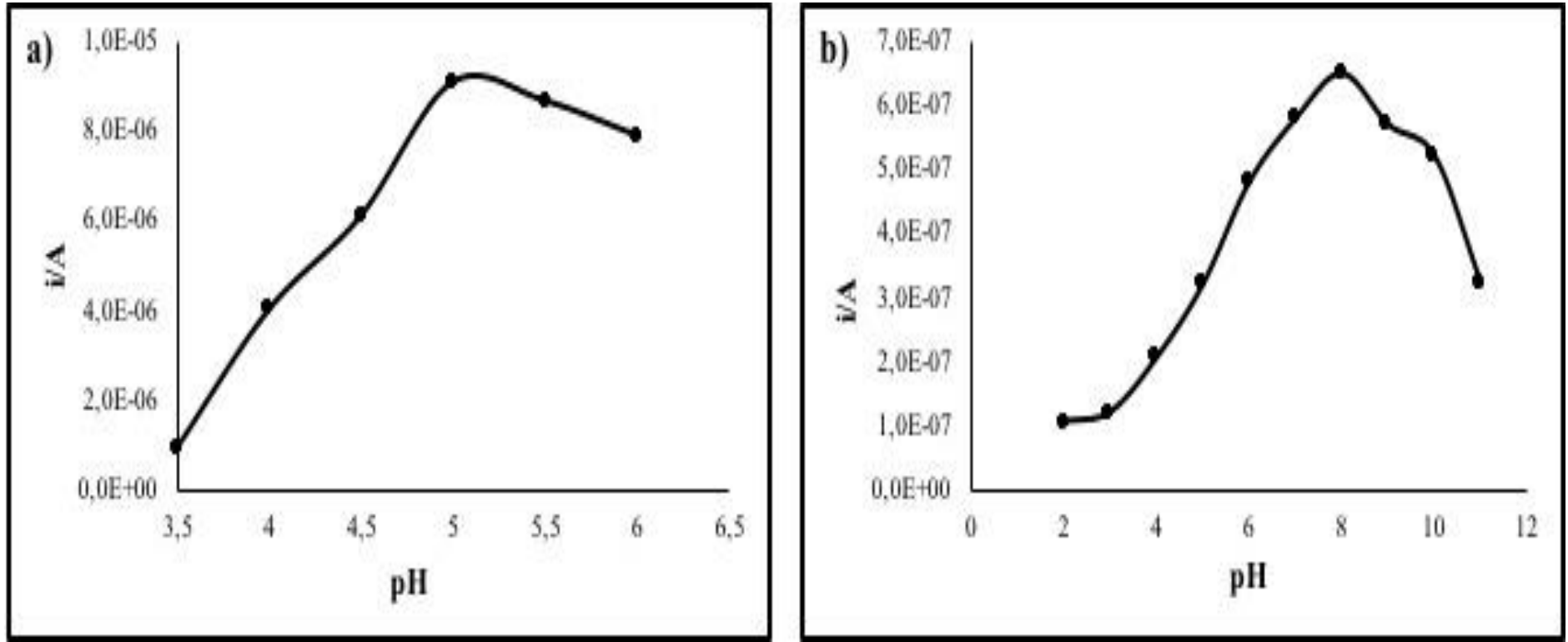

Şekil 3. a) 0,2 mM ampisilinin asetat tamponunda pH-akım grafiği b)1,0 mM penisilin V'nin Britton-Robinson tamponunda pH-akım grafiği

Penisilin V için en yüksek yükseltgenme akım değeri, pH 8,0 Britton-Robinson tampon çözeltisinde gözlenmesine rağmen pH 6,0 Britton-Robinson tamponunda elde edilen voltamogramlarda daha keskin pikler ve tekrarlanabilir akım değerleri elde edilmesinden dolayı penisilin V'nin farmasötik numunedeki analizi bu ortamda gerçekleştirilmiştir.

Ampisilin analizi için pH 5,0 asetat tamponunda $0,02 \mathrm{mM}$ ile $0,20 \mathrm{mM}$ aralığındaki yedi farklı ampisilin derişimlerine karşı elde edilen pik akımları grafiğge geçirildiğinde; bu grafiğin lineer olduğu $\left(\mathrm{R}^{2}=0,9998\right)$ görülmüştür (Şekil 4a). Elde edilen doğrusal kalibrasyon fonksiyonun korelasyon katsayısının 1'e çok yakın olduğu gözlenmiştir. Penisilin V'nin kalibrasyon fonksiyonunun doğrusal aralığınının belirlenmesinde $0,5 \mathrm{mM}$ ile $10,0 \mathrm{mM}$ arasında $\mathrm{pH}$ 6,0 Britton-Robinson tamponunda farklı derişimlerde çözeltiler hazırlanmıştır. Penisilin V için bu konsantrasyonlar aralı̆̆ında altı noktalı kalibrasyon eğrisi oluşturulmuştur. Penisilin V derişimlerine karşı pik akım değerleri grafiğe geçirildiğinde lineer bir doğru $\left(\mathrm{R}^{2}=0,9996\right)$ elde edilmiştir (Şekil 4b).
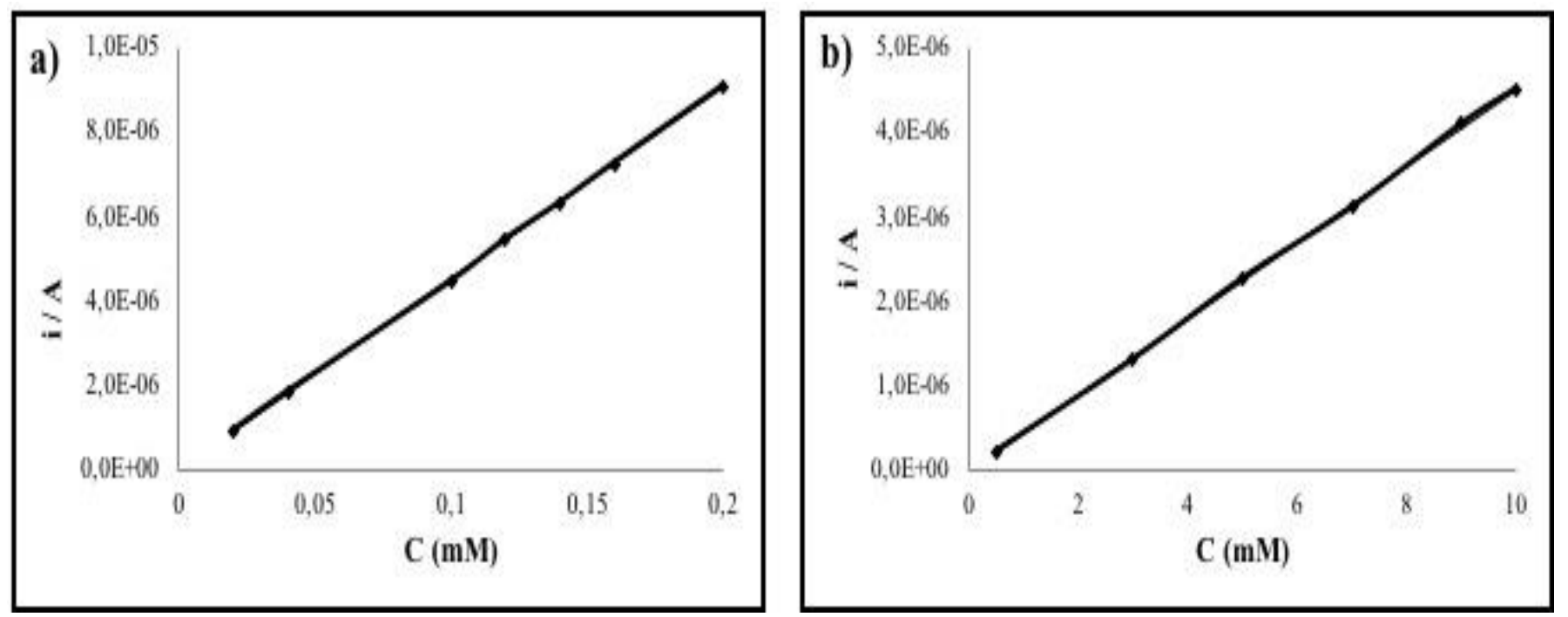

Şekil 4. DPV ile a) ampisilin (pH 5,0 asetat tamponu 0,02-0,20 mM derişim aralığı) ve b) penisilin V'ye (pH 6,0 Britton-Robinson tamponu 0,5-10,0 mM derişim aralığı) ait yükseltgenme akımları 
Belirlenen optimum ortamlardaki ampisilin ve penisilin V derişimi ve akım cevapları arasındaki doğrusal ilişkiden gözlenebilme (LOD) ve kantitatif tayin (LOQ) sınırları hesaplanmış $(\mathrm{S} / \mathrm{N}=3$ ) ve Tablo 1'de verilmiştir.

Tablo 1. Ampisilin ve penisilin V için LOD ve LOQ değerleri

\begin{tabular}{ccc}
\hline Bileșik & LOD & LOQ \\
\hline Ampisilin & $4,05 \cdot 10^{-7} \mathrm{M}$ & $1,35.10^{-6} \mathrm{M}$ \\
Penisilin V & $3,07 \cdot 10^{-5} \mathrm{M}$ & $1,02.10^{-4} \mathrm{M}$ \\
\hline
\end{tabular}

Ampisilin ve penisilin $\mathrm{V}$ için yapılan çalışmalar incelendiğinde tayin limitlerinin penisilin $\mathrm{V}$ için $1,5.10^{-5} \mathrm{M}$ ile $5.10^{-8} \mathrm{M}$ aralı̆̆ı̆nda, ampisilin için ise 1,66.10-5 M civarında bulunduğu görülmüştür [Svorc vd., 2012a; Bergamini vd., 2006; Chen vd., 2010; Svorc vd., 2012b]. Çalışmalarımızda bu bileşikler için elde edilen tayin limitleri literatür verilerine yakın değerlerde olduğu belirlenmiştir [Sarı, 2013].

Ampisina isimli farmasötik numunedeki ampisilin ve PEN-OS 1000 isimli farmasötik numunedeki penisilin V'nin tayini kalem ucu grafit elektrot kullanarak diferansiyel puls voltametri yöntemi ile gerçekleştirilmiştir. Numune analizi, en yüksek yükseltgenme akımının elde edildiği; ampisilin için pH 5,0 asetat tamponunda, penisilin V için pH 6,0 Britton-Robinson tampon çözeltisinde yapılmıştır. Tabletlerin çözülmesi ile hazırlanan çözeltiler, kalibrasyon doğrusu aralığına giren ampisilin (Şekil 5a) ve penisilin V (Şekil 5b) derişimlerine seyreltilmiştir.
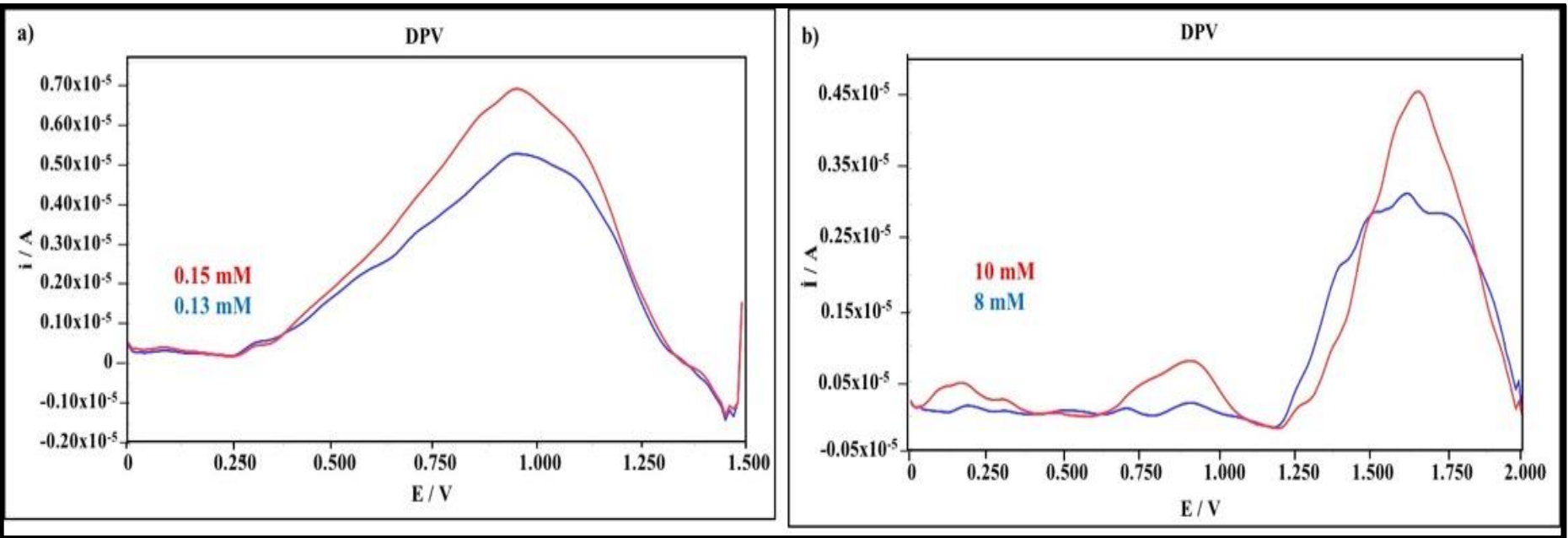

Şekil 5. a) Ampisina farmasötik numunenin $0,13 \mathrm{mM}$ ve $0,15 \mathrm{mM}$ ampisilin derişimleri b) PEN-OS 1000 farmasötik numunenin 8,0 $\mathrm{mM}$ ve $10,0 \mathrm{mM}$ penisilin V derişimleri için alınan DP voltamogramları

Ampisilin ve penisilin V içeren ilaç tabletlerinde yapılan analizlerde elde edilen geri kazanım ve bağıl standart sapma (BSS) değerleri Tablo 2'de verilmiş̧tir. Elektrokimyasal ve kromatografik yöntemlerle penisilin V ve ampisilin içeren ilaçların analizlerinin gerçekleştirildiği çalışmalarda geri kazanım değerleri her iki bileşik için \% 85-102 aralığındadır [Svorc vd., 2012a; Benito-Pena vd., 2009]. Yaptığımız çalışmada ampisilin ve penisilin V için geri kazanım değerleri sırasıyla \% 91,6 ve \% 101,5 olarak bulunmuştur ve bu sonuçlar literatürler ile uyumludur.

Tablo 2. Çalışılan farmasötik numunelerin analiz sonuçları

\begin{tabular}{ccccc}
\hline Numune & Tablet Derişimi & $\begin{array}{c}\text { Tayin Edilen } \\
\text { Derişim }\end{array}$ & \% BSS & Geri Kazanım \\
\hline Ampisina & $5.10^{-5} \mathrm{M}$ & $4,58.10^{-5} \mathrm{M}$ & 0,79 & $\% 91,6$ \\
PEN-OS 1000 & $6.10^{-3} \mathrm{M}$ & $6,09.10^{-3} \mathrm{M}$ & 0,83 & $\% 101,5$ \\
\hline
\end{tabular}

\section{Sonuç}

Yapılan literatür taramasında penisilin grubu bileşiklerin elektrokimyasal davranışlarının incelendiği ve voltametrik tayinlerin yapıldığı az sayıda çalışmaya rastlanmıştır. Bu çalışmalarda[N,N'-etilenbis(salisilidenaminato)]oksovanadyum(IV), [VO(Salen)] ile modifiye edilmiş karbon pasta elektrot, yüzeyinde multi-duvarlı karbon nanotüp ile hematein ve $\beta$-laktamazın ko-immobilizasyonunu içeren camsı karbon elektrot, modifiyesiz bor katkılı elmas elektrotlar kullanılmıştır [Svorc vd., 2012a; Altınöz Erdoğan, 2011; Perçin Özkorucuklu vd., 2008; Özcan vd., 2008]. Bu elektrotların maliyeti yüksek ve hazırlanması zaman alıcıdır. Bu çalışmada çalışma 
elektrotu olarak yüksek elektrokimyasal reaktivitesi, mekanik dayanıklılı̆̆ı, düşük maliyet ve teknoloji gerektirmesi, minyatüleştirme ve yenilenmesinin kolaylığı nedeniyle pek çok analitik uygulamada tercih edilen kalem grafit elektrot kullanılmıştır. Bu elektrodun aktif yüzey alanı fazladır ve düşük derişimlerdeki analitlerin tayininde avantaj sağlamaktadır.

$\mathrm{Bu}$ çalışmada ampisilin ve penisilin V'nin elektrokimyasal davranışları farklı destek elektrolit ve farklı pH'larda hazırlanan çözeltilerde kalem ucu grafit elektrot kullanılarak diferansiyel puls yöntemi ile incelenmiştir. Ampisilin ve penisilin V'nin standart ve farmasötik örneklerde tayinleri yapılmıştır. Elde edilen sonuçlar ampisilin ve penisilin V tayininde kromatografik ve optik yöntemlere alternatif bir yöntem olarak kalem grafit elektrodun kullanıldığı hızlı, kolay, duyarlı ve herhangi bir ayırma işlemine gerek duyulmayan diferansiyel puls voltametri yönteminin kullanılabileceğini göstermiştir [Sarı, 2013]. Kullanılan yöntem basit ve malzemelerin maliyeti düşüktür. Bu yönüyle ticari açıdan önemli bir etken olan düşük maliyetli tayinlerin yapılmasını mümkün kılmaktadır.

\section{Teşekkür}

Bu çalışma 3400-YL1-12 numaralı Süleyman Demirel Üniversitesi BAP Lisansüstü Tez projesi kapsamında desteklenmiştir.

\section{Kaynakça}

Akalın, H.E. (1994), Antibiyotik tedavisinde temel ilkeler, Klinik uygulamada antibiyotikler ve diğer antimikrobiyal ilaçlar, Güneș Kitabevi, Ankara, s. 1-9.

Altınöz Erdoğan, D. (2011), Bazı depresan ilaç etken maddelerin tayini için elektrokimyasal yöntemler gelişstirilmesi ve bunların analitik uygulamaları, Doktora Tezi, Ankara Üniversitesi/Fen Bilimleri Enstitüsü, Ankara, 131s.

Aydogdu, G., Gunendi, G., Zeybek, D.K., Zeybek, B., Pekyardimci, S. (2014), A novel electrochemical DNA biosensor based on poly(5-amino-2-mercapto-1,3,4-thiadiazole) modified glassy carbon electrode for the determination of nitrofurantoin, Sensors Actuators B-Chemical, 197, 211-219.

Benito-Pena, E., Urraca, J.L., Moreno-Bondi, M.C. (2009), Quantitative determination of penicillin V and amoxicillin in feed samples by pressurised liquid extraction and liquid chromatography with ultraviolet detection, Journal of Pharmaceutical Biomedical Analysis, 49, 289-294.

Bergamini, M.F., Teixeira, M.F.S., Dockal, E.R., Bocchi, N., Cavalheiro, É.T.G. (2006), Evaluation of different voltammetric techniques in the determination of amoxicillin using a carbon paste electrode modified with [n, n'etilenbis(salisilidenaminato)]oksovanadyum(IV), Journal Electrochemical Society, 153, E94-E98.

Chen, B., Ma, M., Su, X. (2010), An Amperometric penicillin biosensor with enhanced sensitivity based on co-1mmobilization of carbon nanotubes, hematein and $\beta$-lactamase on glassy carbon electrode, Analytica Chimica Acta, 674, 89-95.

Das, P., Barbora, L., Das, M., Goswami, P. (2014), Highly sensitive and stable laccase based amperometric biosensor developed on nano-composite matrix for detecting pyrocatechol in environmental samples, Sensors Actuators B-Chemical, 192, 737-744.

Gökahmetoğlu, S.D. (1997), Yeni kuşak $\beta$-Laktam antibiyotiklere dirençli pseudomonas suşlarında bulunan $\beta$-laktamazların "isoelectric focusing" yöntemi ile tiplendirilmesi, Uzmanlık Tezi, Erciyes Üniversitesi, Kayseri, 80s.

Gürler, B., Percin-Ozkorucuklu, S., Kır, E. (2013), Voltammetric behavior and determination of doxycycline in pharmaceuticals at molecularly imprinted and non-imprinted overoxidized polypyrrole electrodes, Journal of Pharmaceutical Biomedical Analysis, $84,263-268$.

Khan, A.A.P., Mohd, A., Bano, S., Siddiqi, K.S., Asiri, A.M. (2015), Spectrophotometric methods for the determination of ampicillin by potassium permanganate and 1-chloro-2,4-dinitrobenzene in pharmaceutical preparations, Arabian Journal of Chemistry, 8, 255263.

Lima, A.B., Torres, L.M.F.C., Guimaraes, C.F.R.C., Verly, R.M., Da Silva, L.M., Carvalho, A.D., Dos Santos, W.T.P. (2014), Simultaneous determination of paracetamol and ibuprofen in pharmaceutical samples by differential pulse voltammetry using a boron-doped diamond electrode, Journal Brazil Chemical Society, 25, 478-483.

Medvedovici, A., Ionescu. M., Mircioiu, C., David, V. (2002), Optimization of a liquid-liquid extraction method for hplc-dad determination of penicillin-V in human plasma, Microchemical Journal, 72, 85-92.

Özcan, L., Şahin, M., Şahin, Y. (2008), Electrochemical preparation of a molecularly imprinted polypyrrole modified pencil graphite electrode for determination of ascorbic acid. Sensors, 8, 5792-5805.

Perçin Özkorucuklu, S., Şahin, Y., Alsancak, G. (2008), Voltammetric behaviour of sulfamethoxazole on electropolymerizedmolecularly imprinted overoxidized polypyrrole, Sensors, 8, 8463-8478.

Sarı, M. (2013), Bazı penisilinlerin elektrokimyasal karakterizasyonu ve voltametrik tayinleri, Yüksek lisans tezi, Süleyman Demirel Üniversitesi/Fen Bilimleri Enstitüsü, Isparta, 83s.

Svorc, L., Sochr, J., Rievaj, M., Tomcik, P., Bustin, D. (2012a.), Voltammetric determination of penicillin V in pharmaceutical formulations and human urine using a boron-doped diamond electrode, Bioelectrochemistry, 88, 36-41.

Svorc, L., Sochr, J., Tomcik, P., Rievaj, M., Bustin, D. (2012b), Simultaneous determination of paracetamol and penicillin V by squarewave voltammetry at a bare boron-doped diamond electrode, Electrochimica Acta, 68, 227-234.

Yanmaz, E. (2010), Elektron konformasyonel-genetik algoritma Qsar metodu ile penisilin türevlerine ait farmakor gruplartn belirlenmesi ve biyoaktivite hesabl, Yüksek lisans tezi, Erciyes Üniversitesi, Kayseri, 142s. 